\title{
Sports Dietitians Australia Position Statement: Nutrition for Exercise in Hot Environments
}

\author{
Alan J. McCubbin \\ Monash University \\ Michelle M. Cort \\ Cricket Australia \\ Siobhan T. Crawshay
Paralympics Australia \\ Stephanie K. Gaskell \\ Monash University \\ Ollie Jay \\ University of Sydney \\ Gregory Shaw \\ Swimming Australia
}

\author{
Bethanie A. Allanson \\ Cricket Australia \\ Ricardo J.S. Costa \\ Monash University \\ Ben Desbrow \\ Griffith University \\ David Hughes \\ Australian Institute of Sport \\ Benita J. Lalor \\ Australian Catholic University and \\ Australian Sailing \\ Julien D. Périard \\ University of Canberra
}

\author{
Joanne N. Caldwell Odgers \\ Monash University \\ Gregory R. Cox \\ Bond University \\ Eliza G. Freney \\ Cricket Australia \\ Chris Irwin \\ Griffith University \\ Megan L.R. Ross \\ Australian Institute of Sport and \\ Australian Catholic University \\ Louise M. Burke \\ Australian Institute of Sport and \\ Australian Catholic University
}

It is the position of Sports Dietitians Australia (SDA) that exercise in hot and/or humid environments, or with significant clothing and/or equipment that prevents body heat loss (i.e., exertional heat stress), provides significant challenges to an athlete's nutritional status, health, and performance. Exertional heat stress, especially when prolonged, can perturb thermoregulatory, cardiovascular, and gastrointestinal systems. Heat acclimation or acclimatization provides beneficial adaptations and should be undertaken where possible. Athletes should aim to begin exercise euhydrated. Furthermore, preexercise hyperhydration may be desirable in some scenarios and can be achieved through acute sodium or glycerol loading protocols. The assessment of fluid balance during exercise, together with gastrointestinal tolerance to fluid intake, and the appropriateness of thirst responses provide valuable information to inform fluid replacement strategies that should be integrated with event fuel requirements. Such strategies should also consider fluid availability and opportunities to drink, to prevent significant under- or overconsumption during exercise. Postexercise beverage choices can be influenced by the required timeframe for return to euhydration and co-ingestion of meals and snacks. Ingested beverage temperature can influence core temperature, with cold/icy beverages of potential use before and during exertional heat stress, while use of menthol can alter thermal sensation. Practical challenges in supporting athletes in teams and traveling for competition require careful planning. Finally, specific athletic population groups have unique nutritional needs in the context of exertional heat stress (i.e., youth, endurance/ultra-endurance athletes, and para-sport athletes), and specific adjustments to nutrition strategies should be made for these population groups.

Keywords: fluid, food, heat, hydration, thermoregulation

\footnotetext{
McCubbin, Costa, and Gaskell are with the Department of Nutrition, Dietetics and Food, Monash University, Notting Hill, Victoria, Australia. Allanson, Cort, and Freney are with the High Performance Department, Cricket Australia, Albion, Queensland, Australia. Caldwell Odgers is with the Department of Physiology, Monash University, Clayton, Victoria, Australia. Cox is with the Faculty of Health Sciences \& Medicine, Bond University, Gold Coast, Queensland, Australia. Crawshay is with Paralympics Australia, Sydney Olympic Park, New South Wales, Australia. Desbrow and Irwin are with the School of Allied Health Sciences, Griffith University, Queensland, Australia. Hughes, Ross, and Burke are with the Australian Institute of Sport, Bruce, Australian Capital Territory, Australia. Jay is with the Thermal Ergonomics Laboratory, University of Sydney, New South Wales, Australia. Lalor is with the School of Behavioural and Health Sciences, Australian Catholic University, Melbourne, Victoria, Australia; and Australian Sailing, St Leonards, New South Wales, Australia. Ross and Burke are also with the Centre for Exercise and Nutrition, Mary MacKillop Institute for Health Research, Australian Catholic University, Melbourne, Victoria, Australia. Shaw is with the High Performance Unit, Swimming Australia, Brisbane, Queensland, Australia. Périard is with the Research Institute for Sport and Exercise, University of Canberra, Bruce, Australian Capital Territory, Australia. McCubbin (alan.mccubbin@ monash.edu) is corresponding author.
} 
Exercise in hot and/or humid environments, or with significant clothing and/or equipment that prevents loss of body heat, can lead to exertional heat stress. Numerous sporting competitions are regularly held in outdoor environments in such conditions including high-intensity endurance events (e.g., 10-km road races and half-marathons, cycling time trials), ultra-endurance events (e.g., Badwater Ultramarathon, Ironman World Championships, and Marathon des Sables), and team (e.g., cricket and soccer) and racquet (e.g., tennis) sports played during summer months. Meanwhile, scenarios involving sports in hot and/or humid indoor environments include squash and motor racing, where in the latter case, the driver/rider can be exposed to ambient temperatures $>45{ }^{\circ} \mathrm{C}$ while wearing protective clothing and equipment. Major sporting events in hot and/or humid locations, such as the 2019 International Association of Athletics Federations World Championships in Doha, Qatar, and the 2020 Summer Olympic Games in Tokyo, Japan, merit special consideration because the conditions pose a significant challenge for a large number of competitors (Gerrett et al., 2019) and require specific preparation.

What should be evident from these scenarios is that the thermal challenges faced by athletes are significant in both magnitude and variety, with individual factors such as the environmental conditions, metabolic heat production, performance characteristics, and logistics of athlete behavior around the exercise session creating unique concerns, as well as dictating the type of solutions that might be developed. Indeed, prolonged exertional heat stress can perturb the thermoregulatory, cardiovascular, and gastrointestinal systems, posing significant concerns for an athlete's health and performance. It is the position of Sports Dietitians Australia that exertional heat stress can significantly affect an athlete's nutritional status, but careful planning and implementation of nutrition strategies can assist him or her to optimize health and performance outcomes in such conditions. The following position statement summarizes these issues and the nutrition and hydration strategies with which they can be addressed.

\section{Physiological Effects of Exertional Heat Stress}

\section{Thermoregulation}

During exercise, high body temperatures arise from excess heat storage due to sustained imbalance between internal heat production and heat dissipation at the skin surface. Heat is generated in large quantities as a by-product of elevated rates of metabolism, supporting muscle contractions. Simultaneously, heat can be gained or lost via convection and radiation, and dissipated through the evaporation of sweat (Gagge \& Gonzalez, 1996). Convective heat exchange is driven by temperature differences between the skin and air (in the shade) and modified by wind speed. Radiative heat exchange is determined by differences between skin temperature and mean radiant temperature, which on a clear summer day can be $10-15^{\circ} \mathrm{C}$ higher than air temperature (Jay \& Morris, 2018). Evaporative heat loss potential is governed by the absolute humidity difference between the skin and air and increases with wind speed. Clothing and equipment serve as a heat loss barrier dependent on garment insulation and water vapor permeability. A simple definition of "heat stress" is therefore not possible, as heat strain across a range of different air temperatures will vary according to the activity and clothing/equipment worn, as well as the prevailing sun exposure, humidity, and wind speed (Figure 1).

To minimize heat storage and prevent excessive core temperature increases, humans vasodilate and sweat. Neurons controlling these responses originate in the preoptic area of the hypothalamus, a small central region of the brain. Afferent input from thermoreceptors located in deep body structures and in the layer of the skin enables the hypothalamus to receive constant information about the thermal status of the body (Morrison, 2011). Elevations in core temperature of $>0.2^{\circ} \mathrm{C}$ can elicit cutaneous vasodilation, directing a greater volume of blood toward the skin to redistribute heat content and increase convective and radiative heat loss as skin temperature rises (Cramer \& Jay, 2019). If nonevaporative heat loss is insufficient to offset elevated rates of heat production, core

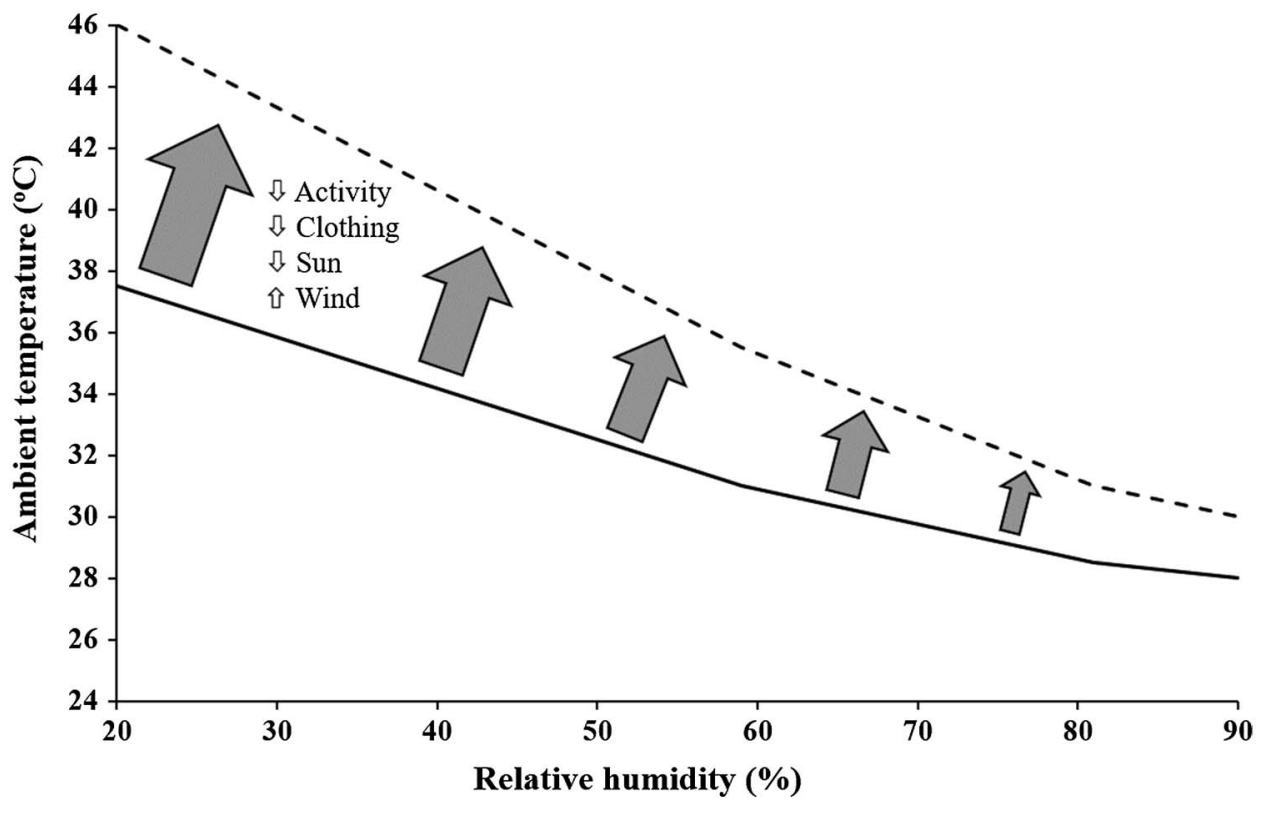

Figure 1 - A conceptual schematic illustrating that a given level of heat strain (solid and dotted lines) is dependent on the two personal parameters of clothing and activity and the four environmental parameters of ambient temperature, humidity, wind speed, and radiant temperature (sun exposure). 
temperature continues to rise and eccrine sweat glands are activated via acetylcholine release (Gagnon \& Crandall, 2018). If the ambient temperature permits the rate of sweat evaporation to balance the heat production, then core temperature will reach an elevated, but usually safe, plateau. However, when heat production exceeds this capacity, body temperature will continue to rise in a state known as uncompensable heat stress.

\section{Gastrointestinal Function and Integrity}

The impact of exercise in hot environments on the gastrointestinal tract merits special attention, as it contributes to the pathophysiology of exertional heat illnesses (EHIs) and/or gastrointestinal complications that compromise the athlete's capacity to address their nutritional goals and optimize thermoregulation. Prolonged exercise in hot ambient conditions, resulting in a core temperature $\geq 39.0{ }^{\circ} \mathrm{C}$, exacerbates the perturbations to gastrointestinal integrity, function, and systemic responses compared with exercise in cooler conditions (Costa et al., 2019a). Such perturbations, known as exercise-induced gastrointestinal syndrome, have been linked to performance- debilitating gastrointestinal symptoms and clinical implications ranging from mild inconvenience to fatality (Costa et al., 2017). These multifaceted outcomes reflect two primary physiological changes, which occur at the onset of exercise and are exacerbated by thermal stress, creating a structural and functional burden to the gastrointestinal system (Figure 2). Redistribution of blood flow away from the gastrointestinal tract and toward skeletal muscles (i.e., metabolic kinetics) and peripheral circulation (i.e., thermoregulation) results in reduced total splanchnic perfusion and subsequent gastrointestinal ischemia (Grootjans et al., 2016; van Wijck et al., 2011). Concomitantly, an increase in sympathetic activation reduces overall gastrointestinal functional capacity, possibly via suppressed myenteric and submucosal plexus activity (Costa et al., 2017; Horner et al., 2015; Strid et al., 2011). The initiation of these physiological responses is dependent on the exercise stress per se (i.e., intensity, duration, and modality) but is exacerbated with heat exposure (Costa et al., 2017, 2019a). The secondary outcomes of these exercise-associated gastrointestinal abnormalities include mucosal erosion, epithelial cell injury and dysfunction, tight junction damage and dysfunction, luminal bacterial endotoxin translocation, local epithelium and systemic

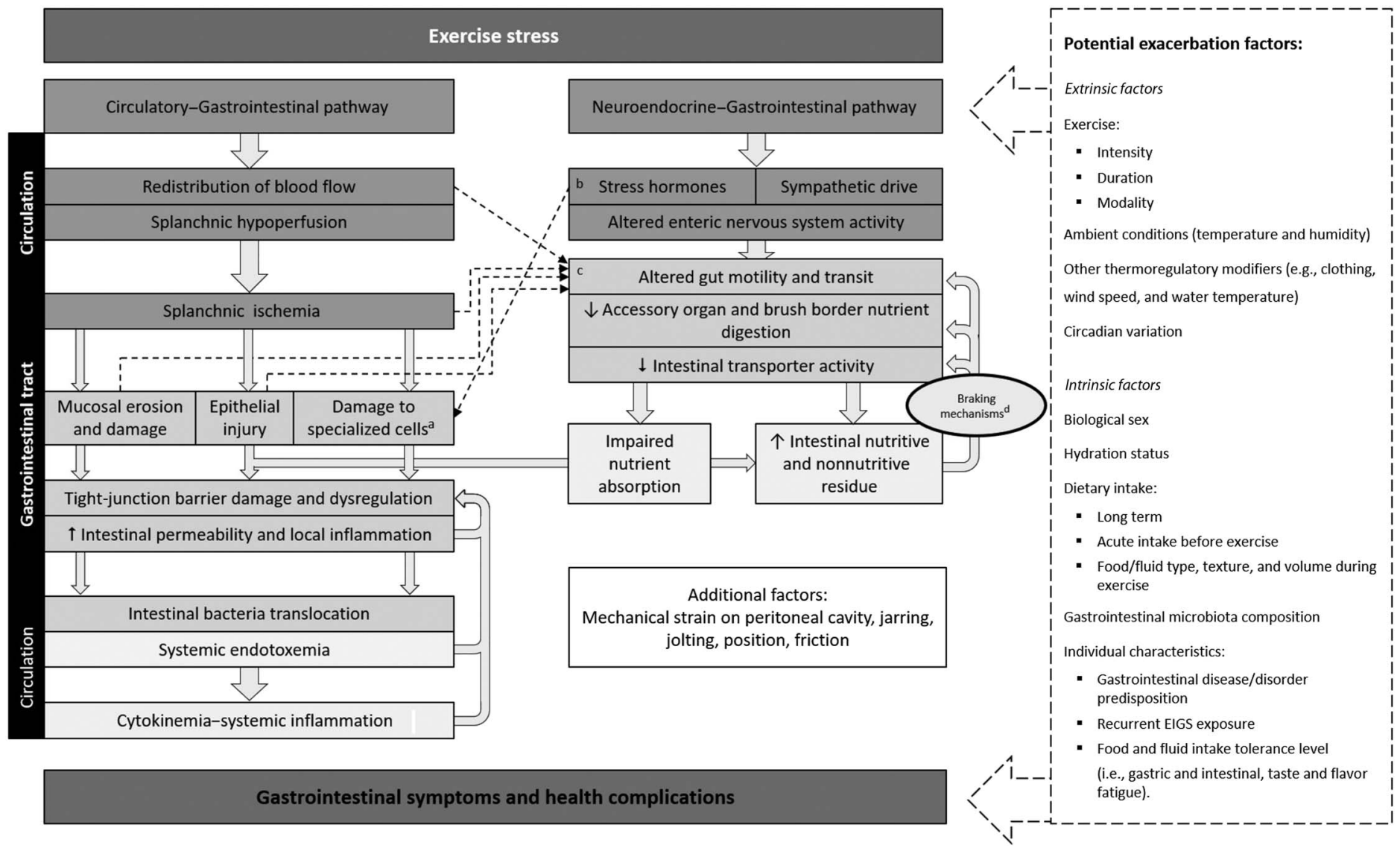

Figure 2 - Schematic description of exercise-induced gastrointestinal syndrome: Physiological changes in circulatory and neuroendocrine pathways at the onset of exercise resulting in perturbed gastrointestinal integrity and function, and may lead to gastrointestinal symptoms, and/or acute or chronic health complications. Adapted with permission from "Systematic Review: Exercise-Induced Gastrointestinal Syndrome-Implications for Health and Disease," by Costa et al., 2017, Alimentary Pharmacology and Therapeutics, 46, pp. 246-265. 'Specialized antimicrobial protein-secreting (i.e., Paneth cells) and mucus-producing (goblet cells) cells, aid in preventing intestinal-originating pathogenic microorganisms gaining entry into systemic circulation. ${ }^{\mathrm{b}}$ Splanchnic hypoperfusion and subsequent intestinal ischemia and injury (including mucosal erosion) results in direct (egg, enteric nervous system, and/or enteroendocrine cell) or indirect (egg and nutrient malabsorption) alterations to gastrointestinal motility. ${ }^{\mathrm{c}}$ Increase in neuroendocrine activation and suppressed submucosal and myenteric plexus result in epithelial cell loss and subsequent perturbed tight junctions (Holzer et al., 2017; Barrett, 2012). ${ }^{\mathrm{d}}$ Gastrointestinal brake mechanisms: Nutritive and nonnutritive residue along the small intestine, and inclusive of terminal ileum, results in neural and enteroendocrine negative feedback to gastric activity (Miall et al., 2018; Shin et al., 2013; Layer et al., 1990; van Avesaat et al., 2015; van Citters \& Lin, 2006). 
innate/adaptive immune cell and inflammatory responses, suppressed gastric emptying, and suppressed nutrient digestion and absorption (Costa et al., 2017). Current and emerging evidence shows that hot and/or humid ambient conditions play a key role in determining the magnitude of exercise-induced gastrointestinal syndrome (Costa et al., 2019a; Pires et al., 2017, 2018).

\section{Effects of Exertional Heat Stress on Performance and Health}

Increases in thermal strain during prolonged exercise (i.e., elevated skin, muscle, and core body temperatures) progressively impair aerobic performance (Table 1; Ely et al., 2007). This impairment is linked to a thermoregulatory-mediated rise in cardiovascular strain, which contributes to decreased maximal aerobic capacity (Périard et al., 2011; Périard \& Racinais, 2015), and a potential hyperthermia-induced reduction in voluntary drive (i.e., motivation; Bruck \& Olschewski, 1987). Exertional heat stress also induces greater reliance on muscle glycogen and anaerobic metabolism (Febbraio et al., 1994), which may prematurely deplete endogenous glycogen stores during endurance exercise. In contrast, a rise in whole-body temperature, particularly muscle temperature, enhances the performance of explosive short-duration activities such as sprinting and jumping (Bergh \& Ekblom, 1979; Sargeant, 1987), via temperature-related improvements in metabolic and contractile function (Allen et al., 2008; Fitts, 1994). While single efforts may be improved in hot environmental conditions, repeated-sprint activities may reach a tipping point, where muscle temperature-related benefits are overridden by exacerbated cardiovascular and metabolic responses (Girard et al., 2015). In team sport athletes (e.g., football), the effects of environmental heat stress appear to include both an impairment and improvement in performance compared with cool conditions (Table 1). More specifically, total and high-intensity running distances are decreased, whereas peak running speed is maintained or improved (Aughey et al., 2014; Mohr et al., 2012).

Regardless of performance effects, the risk of EHI, a continuum of medical conditions that can affect physically active individuals in hot and cool environments, is increased by the development of hyperthermia. The severity of EHI can escalate from heat exhaustion, to heat injury, and on to heat stroke (Leon \& Bouchama, 2015). Heat exhaustion is associated with a body core temperature of $38.5-40{ }^{\circ} \mathrm{C}$, dehydration, possibly hot dry skin due to the absence of sweating, and an inability to maintain cardiac output. A heat injury is characterized by organ (e.g., liver) and tissue (e.g., gut) damage with a body temperature typically $>40{ }^{\circ} \mathrm{C}$. In the most severe EHI, exertional heat stroke, characterized by a body temperature $>40{ }^{\circ} \mathrm{C}$, profound central nervous system dysfunction (e.g., combativeness, delirium, seizures, and coma), and organ and tissue damage, can lead to death. Other common but relatively benign conditions such as muscle cramping do not form part of the EHI continuum.

\section{Heat Acclimation and Acclimatization}

Heat acclimation is the process of exposing an individual to repeated heat stress in a controlled or artificial environment about 7-14 days, with the aim of increasing whole-body temperature and inducing profuse sweating. In contrast, heat acclimatization occurs in a natural environment with changes of season, or travel from cool to hot locations (Armstrong \& Maresh, 1991). These two terms are often used interchangeably as they both induce physiological adaptations that can benefit athletic performance during prolonged events (Périard et al., 2015). Initial adaptations, including plasma volume $\left(P_{\mathrm{v}}\right)$ expansion, enhanced fluid balance, reduced heart rate, and decreased ratings of perceived exertion, begin to emerge in 3-5 days of acclimation (Gisolfi \& Cohen, 1979; Patterson et al., 2004). Reductions in resting core temperature, increased sweat rate, and decreased sweat sodium $\left(\left[\mathrm{Na}^{+}\right]_{\text {sweat }}\right)$ and chloride $\left(\left[\mathrm{Cl}^{-}\right]_{\text {sweat }}\right)$ concentrations develop over a longer time frame (e.g., 3-10 days; Gerrett et al., 2019). Interestingly, the increase in sweat rate is offset by reduced $\left[\mathrm{Na}^{+}\right]_{\text {sweat }}$ to the extent that overall sweat sodium losses following acclimation are equivalent or lower to those observed prior to heat acclimation (Chinevere et al., 2008).

Although heat acclimation is the most important intervention that athletes can undertake in preparation for competing in the heat (Racinais et al., 2015), the process of becoming acclimated can be challenging. Notably, athletes may need to adjust absolute training intensity and volume during heat training sessions compared with typical sessions undertaken in cooler conditions, or risk overreaching (Schmit et al., 2018) and experiencing lethargy and sleep disturbances (Taylor \& Cotter, 2006). However, different approaches can be adopted based on available time and resources, as well as when the athletes will be arriving to the competition venue (Saunders et al., 2019). It should be recognized that the benefits of heat acclimation may offer different advantages, and possible disadvantages, according to the event characteristics. For example, sports in which protective clothing impedes sweat

\section{Table 1 Influence of Environmental Heat Stress on the Development of Whole-Body Hyperthermia and Its Effects on Exercise Performance Relative to Exercising in Cool Ambient Conditions}

\begin{tabular}{ll}
\hline Exercise/sport & Influence of environmental heat stress \\
\hline Aerobic/endurance & $\begin{array}{l}\text { Performance is progressively impaired. A given absolute workload (e.g., speed, power) is more difficult to maintain } \\
\text { as hyperthermia and cardiovascular strain develop. }\end{array}$ \\
$\begin{array}{l}\text { Single brief maximal } \\
\text { efforts }\end{array}$ & $\begin{array}{l}\text { Performance is acutely improved. Explosive short-duration performance (e.g., speed, power) is enhanced by a rise in } \\
\text { whole-body and skeletal muscle temperature. }\end{array}$ \\
$\begin{array}{l}\text { Repeated brief maximal } \\
\text { efforts }\end{array}$ & $\begin{array}{l}\text { Performance is acutely improved and then progressively impaired. Initial maximal performance (e.g., speed, power) } \\
\text { may be enhanced in response to muscle temperature-related benefits, but subsequent efforts impaired due to lack of } \\
\text { recovery and exacerbated cardiovascular/metabolic responses. }\end{array}$ \\
Team sports & $\begin{array}{l}\text { Aerobic/endurance component of performance is progressively impaired and single brief maximal efforts maintained } \\
\text { or improved. A given absolute workload is more difficult to sustain as hyperthermia and cardiovascular strain develop, } \\
\text { leading to a decrease in aerobic performance (e.g., total distance covered). } \\
\text { Explosive short-duration performance (e.g., single sprint) is maintained or enhanced due to a rise in whole-body } \\
\text { and skeletal muscle temperature. }\end{array}$ \\
\hline
\end{tabular}


evaporation (e.g., motor racing) will not benefit from earlier and amplified sweat rates (Taylor \& Cotter, 2006); nevertheless, reductions in resting core temperature and thermal perception, along with expanded $P_{\mathrm{v}}$, may still be valuable.

\section{Fluid and Electrolyte Balance During Exertional Heat Stress and Acclimation}

The redistribution of blood flow and thermoregulatory sweating in response to exertional heat stress result in significant changes in body water and electrolyte balance (Sawka et al., 2007). Unreplaced sweat losses reduce total body water (TBW) and $P_{\mathrm{v}}$, resulting in reduced cutaneous blood flow, increased core temperature, greater cardiovascular strain (i.e., increased heart rate and reduced cardiac output), and increased risk of exercise-induced gastrointestinal syndrome for the same exercise task (Costa et al., 2019b; Trangmar \& GonzálezAlonso, 2017). Thermoregulatory sweat also contains several solutes including $\mathrm{Na}^{+}$and $\mathrm{Cl}^{-}$, the only two electrolytes whose excretion is known to be physiologically regulated (Bovell, 2015). Whole-body $\left[\mathrm{Na}^{+}\right]_{\text {sweat }}$ varies considerably (11-87 mmol/L), which combined with an equally variable sweat rate (typical range $150-3,500 \mathrm{ml} / \mathrm{hr}$ ), produces large interindividual differences in $\mathrm{Na}^{+}$losses during exercise ( $\sim 50$ to $3,500 \mathrm{mg} / \mathrm{hr}$; Barnes et al., 2019). There is also substantial intraindividual variation in sweat $\mathrm{Na}^{+}$losses, with exercise intensity (Holmes et al., 2016), hydration status (Morgan et al., 2004), airflow (Saunders et al., 2005), habitual $\mathrm{Na}^{+}$intake (McCubbin et al., 2019a), and heat acclimation status (Chinevere et al., 2008), influencing the response. Such factors, however, explain less than $20 \%$ of the variation in sweat $\mathrm{Na}^{+}$losses between athletes (Baker et al., 2016).

Fluid and $\mathrm{Na}^{+}$replacement during exertional heat stress has differing effects on TBW, $P_{\mathrm{v}}$, plasma osmolality $\left(P_{\mathrm{Osm}}\right)$, and plasma $\mathrm{Na}^{+}$concentration $\left(\left[\mathrm{Na}^{+}\right]_{\text {plasma }}\right)$, depending on both their absolute and relative quantities compared with sweat losses. Consuming $\mathrm{Na}^{+}$ during exercise can result in greater $P_{\mathrm{v}}$ retention than water alone, via increased ad libitum fluid intake subsequent to increased osmotic thirst drive (Hoffman et al., 2019), reduced diuresis, and/or movement of fluid from the intracellular to extracellular space (Sanders et al., 2001). However, the influence on $\left[\mathrm{Na}^{+}\right]_{\text {plasma }}$ is minor (Hew-Butler et al., 2015). Athletes often consume $\mathrm{Na}^{+}$during exercise in the belief that it can prevent or treat some scenarios of exercise-associated muscle cramping (McCubbin et al., 2019b). Although evidence from observational studies is somewhat equivocal (Bergeron, 2003; Schwellnus, 2009), recent publications suggest that $\mathrm{Na}^{+}$intake may play a role in altering the frequency threshold in an electrically induced cramping model (Earp et al., 2019; Lau et al., 2019), which warrants further investigation. Finally, specific commentary on the practice of $\mathrm{Na}^{+}$replacement to prevent the development of hyponatremia during prolonged events (McCubbin et al., 2019b) recognizes that although hypovolemic hyponatremia (low $\left[\mathrm{Na}^{+}\right]_{\text {plasma }}$ in concert with hypohydration) does occur in scenarios of prolonged exercise in hot conditions, the most common cause of exercise-associated hyponatremia is excessive fluid intake (Hew-Butler et al., 2015).

\section{Hydration and Electrolyte Status Assessment}

Hydration status can be defined in multiple ways, including absolute values and changes in TBW, $P_{\mathrm{v}}, P_{\mathrm{Osm}}$, and $\left[\mathrm{Na}^{+}\right]_{\text {plasma }}$. No single marker is considered definitive, as changes in fluid balance alter TBW, as well as shifts between intracellular and extracellular fluid compartments (Armstrong, 2007). Methods to assess hydration status are summarized in Table 2. Absolute hydration status is difficult to measure outside laboratory settings and is instead inferred from urinary markers (e.g., urine color, osmolality, or specific gravity); daily variation in body mass (BM); thirst; or ideally a combination of these (Armstrong, 2007). Urinary markers reflect recent homeostatic processes to maintain euhydration and are not a direct assessment of hydration status itself. Therefore, urinary markers are likely to reflect hydration status only when well rested, with waking urine samples considered most valid for this purpose (Armstrong, 2007). Bioelectric impedance analysis is increasingly used to estimate TBW and with some models, extracellular fluid. However, this should only be considered adequate when validated against reference methods and under the same conditions in which validation took place.

Changes in TBW during exercise, including rates of sweat losses, are mostly frequently determined via differences in BM. Calculations of sweat rate should be corrected for food consumption and urinary/fecal losses where relevant (Sawka et al., 2007). $\mathrm{BM}$ changes during ultra-endurance exercise $(>4 \mathrm{hr})$ are likely to overestimate reductions in TBW, and adjustments for substrate oxidation, metabolic water production, glycogen depletion, and respiratory water losses may be necessary (Cheuvront \& Kenefick, 2017; Maughan et al., 2007). Electrolyte losses can be determined from sweat sampling during exercise with the electrolyte of interest measured using appropriate techniques, including some validated for use in field settings (Baker et al., 2014). Methodological considerations for assessing sweat composition are beyond the scope of this statement; readers are directed to a recent comprehensive review on the subject (Baker, 2017). However, it should be highlighted that sweat collection from local sites does not represent whole-body fluid or $\mathrm{Na}^{+}$losses, and corrections should be made to reflect whole-body responses (Baker et al., 2018).

\section{Strategies for Fluid and Electrolyte Intake Before, During, and After Exercise}

Fluid and electrolyte intake strategies before, during, and after exercise must be practical and achievable, considering factors such as the mode, duration and intensity of exercise, event rules, and availability/accessibility of fluids, as well as athlete preferences and gastrointestinal tolerance. These factors will also determine whether athletes should emphasize fluid and electrolyte intake before or during exercise to optimize health and performance.

\section{Preexercise Fluid and Electrolyte Intake}

In general, athletes who are exposed to hot conditions in the days preceding competition should monitor hydration status and adjust drinking habits accordingly to ensure they commence exercise in a euhydrated state (Racinais et al., 2015). Exceptions to this include athletes in sports unaffected by hypohydration, in which a slightly lower BM may be useful (e.g., jumpers). The volume and type of fluids included in immediate (e.g., 1-2 hr pre-event) hydration strategies should be based on current hydration status, the anticipated substrate requirements, and fluid balance challenges during exercise. Ideally, such practices should be well-rehearsed and able to accommodate individual needs and gastrointestinal tolerance. When a significant mismatch between sweat losses and opportunities for fluid intake during exercise is anticipated, pre-event hyperhydration may be useful in reducing the net fluid deficit and its impact on performance.

The co-ingestion of an osmotically active agent can assist with the retention of a pre-event fluid bolus. Acute $\mathrm{Na}^{+}$loading 


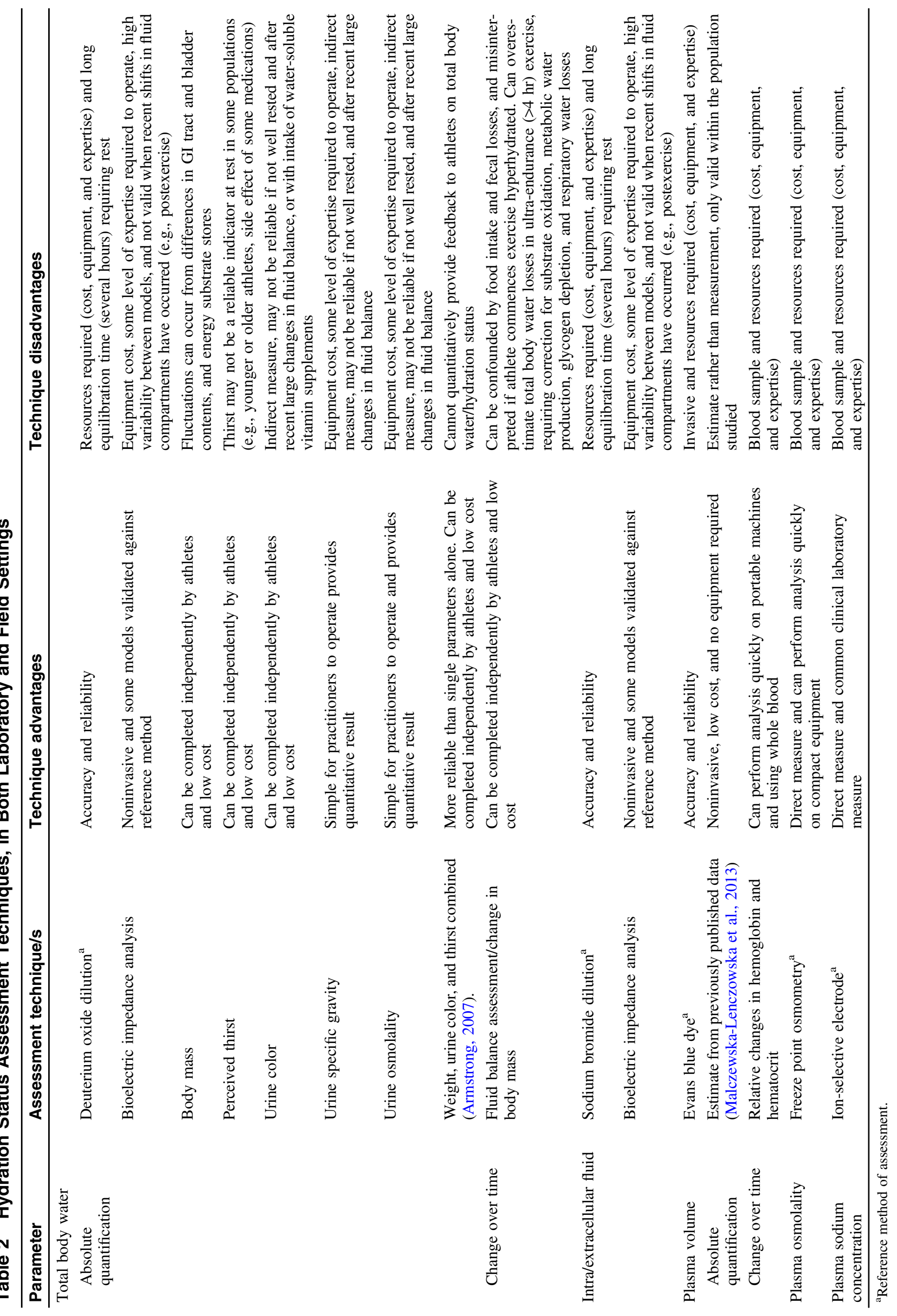


(20-40 mg/kg BM, with $10 \mathrm{ml} / \mathrm{kg}$ BM fluid) $1-2 \mathrm{hr}$ prior to exercise can expand $P_{\mathrm{v}}$ and improve thermoregulation during constant workload exercise in the heat (Hamouti et al., 2014; Sims et al., 2007a, 2007b) and is equally or more effective than $\mathrm{Na}^{+}$loading over an extended period (McCubbin et al., 2019a). Glycerol, a three-carbon alcohol, is another effective osmolyte that enhances fluid retention and results in expansion of $P_{\mathrm{v}}$ and a reduction in urine output. Glycerol was removed from the World Anti-Doping Agency Prohibited List in January 2018 and can now be used for hyperhydration and postexercise rehydration strategies. Studies in endurance athletes support ingestion of $1.2-1.4 \mathrm{~g} / \mathrm{kg}$ fatfree mass (FFM) glycerol in the 90- to 180-min pre-event, in conjunction with $\sim 25 \mathrm{ml} / \mathrm{kg}$ FFM fluid (Goulet et al., 2018; van Rosendal et al., 2010). The combination of glycerol (1.4 g/kg FFM) and sodium $(3.0 \mathrm{~g} / \mathrm{L})$ in $\sim 25 \mathrm{ml} / \mathrm{kg} \mathrm{FFM}$ water may be more effective than either osmolyte alone (Goulet et al., 2018), and such protocols can achieve an additional fluid retention of $\sim 1,300 \mathrm{ml}$ for a 70-kg athlete (Goulet et al., 2018), for up to 4-hr postingestion (Montner et al., 1996; Wingo et al., 2004). The translation into a performance benefit is unclear (Goulet et al., 2007) and may be dependent on ambient conditions and the characteristics of the exercise bout. All protocols should be practiced to determine their effectiveness and potential side effects including gastrointestinal discomfort and headaches.

\section{Fluid and Electrolyte Intake During Exercise}

Opportunities to drink during exercise are often contingent on practicality and/or regulations associated with specific sports/ events. The benefits of fluid consumption during exercise continue to be debated, with contention surrounding the level at which dehydration begins to impair performance and how fluid replacement should occur. Numerous laboratory-based studies suggest that fluid deficits $\geq 2 \% \mathrm{BM}$ are associated with the initiation of impaired exercise performance in hot and/or humid ambient conditions (Adams et al., 2018; Cheuvront et al., 2007; James et al., 2017; Kenefick et al., 2010). However, these studies generally compare protocols involving complete fluid replacement to those where no or minimal fluid is provided and therefore cannot establish a dose-response relationship with regard to optimizing performance. While both ad libitum drinking and planned fluid intake (of a volume greater than ad libitum) improve endurance performance compared with no fluid ingestion (Holland et al., 2017), a recent meta-analysis of exertional heat stress $>1-\mathrm{hr}$ duration concluded that planned fluid intake did not further improve performance beyond that of ad libitum drinking, even with BM losses up to $3.1 \%$ in the ad libitum condition (compared with $<0.5 \%$ with planned drinking), and with exercise intensities up to $90 \%$ of maximum heart rate (Goulet \& Hoffman, 2019). However, the divergence in total fluid intake between planned and ad libitum drinking may increase with exercise duration, particularly under heat stress, and where opportunities to access and ingest fluid during real-life sporting events are more limited than those encountered in laboratory studies. Therefore, individualized fluid replacement plans-informed by prior assessment of fluid balance, perceived thirst, gastrointestinal tolerance, and performance metrics in similar situations, and adjusted according to real-time assessment - can address both the practicality and value of fluid intake during a competitive event.

Fluid choices during exercise should consider substrate requirements, electrolyte content, palatability, and access. Despite previous concern about delayed gastric emptying associated with the addition of solutes to an exercise beverage, carbohydrate-containing drinks can be formulated to minimize this issue (Jeukendrup \& Moseley, 2010); this may address the higher rates of carbohydrate utilization during exercise in the heat (Stellingwerff \& Cox, 2014). Cooler beverages $\left(<22{ }^{\circ} \mathrm{C}\right)$ tend to increase fluid palatability and voluntary consumption during exercise (Burdon et al., 2012), while planned consumption of cold $\left(<10{ }^{\circ} \mathrm{C}\right)$ or iced beverages may convey additional perceptual or performance benefits when exercise is undertaken in hot ambient conditions (Burdon et al., 2010a; Lee et al., 2008). Sodium replacement during prolonged exertional heat stress has been less rigorously studied, preventing conclusions about the value of quantifying or replacing sweat $\mathrm{Na}^{+}$losses to address issues of cramp prevention or optimal performance (McCubbin \& Costa, 2018). Nevertheless, individualized protocols for electrolyte replacement may offer some benefit for specific scenarios until further research can offer a more evidence-based approach. It is noted again that exercise-associated hyponatremia is mostly associated with excessive intake of fluid rather than $\mathrm{Na}^{+}$loss, and its outcomes, secondary to excess fluid osmotically driven into the intracellular pool, including the brain, can be fatal (Hew-Butler et al., 2015). This can be prevented by simply ensuring that fluid intake during exercise does not exceed losses, and it should be noted that ad libitum drinking and drinking to thirst does not necessarily guarantee this (Hew-Butler et al., 2015).

\section{Postexercise Fluid and Electrolyte Intake}

When rapid reversal of moderate-severe fluid deficits is desired postexercise, it may be necessary to drink a volume up to $150 \%$ of the net deficit to account for ongoing fluid losses during the hours of fluid re-equilibration (Sawka et al., 2007). However, the postexercise environment (i.e., food/beverage access), immediate requirements for other recovery purposes (e.g., refueling and adaptation) and overall body composition goals are important contextual considerations. Drinking large volumes of fluid can be challenging in the short term, especially if the athlete has experienced significant thermoregulatory strain or impairment of gastrointestinal integrity/ function during exercise (Russo et al., 2019).

The consumption of nutrients within a rehydration fluid, or in food consumed at the same time, can assist with fluid retention/ minimization of urine losses. Sweat $\mathrm{Na}^{+}$losses during exercise are accompanied by significant renal $\mathrm{Na}^{+}$conservation in the postexercise period (Lichton, 1957), making complete replacement of sweat $\mathrm{Na}^{+}$losses unnecessary. However, the consumption of $\mathrm{Na}^{+}$in rehydration strategies supports less disturbance to $P_{\mathrm{Osm}}$ as $P_{\mathrm{v}}$ is being restored, maintaining the secretion of vasopressin and minimizing subsequent urine production (Evans et al., 2017). The presence of carbohydrate and/or protein is also helpful because the delayed absorption characteristics of such fluids (e.g., milkbased beverages) also reduce $P_{\text {Osm }}$ changes; this has been incorporated into a beverage hydration index (Maughan et al., 2016). However, it is important to recognize that consuming any beverage makes a contribution to total fluid intake and advice to avoid specific beverages (e.g., caffeinated options) may result in lower total fluid intake when these drinks are otherwise part of normal dietary practices (Maughan et al., 2016).

The simultaneous consumption of food is likely to facilitate postexercise rehydration (Campagnolo et al., 2017). When combined with voluntary food intake, the choice of postexercise beverage does not appear to influence restoration of hydration status (Campagnolo et al., 2017; McCartney et al., 2018, 2019), but in the case of energy-containing fluids (e.g., sports drinks and milkbased drinks), it may lead to a greater energy consumption than 
when water is consumed. Therefore, fluid and food intake during recovery should be considered in terms of overall nutrition goals.

\section{Nutritional Pre- and Per-Cooling Strategies During Exercise}

Preparing athletes to safely exercise in uncompensable heat can be addressed by cooling both before (i.e., pre-cooling) and during (i.e., per-cooling) the activity. Different strategies can provide acute relief from the thermal stress posed by training or competing in the heat (Ross et al., 2013). Ingestion of cold/icy drinks (or internal cooling strategies) also provides opportunities to simultaneously address other exercise goals, such as maintaining fluid balance (Sawka et al., 2007), providing nutrient support (Wendt et al., 2007), defending the integrity of the gastrointestinal tract (Snipe et al., 2018), and alleviating thermal discomfort (Stevens et al., 2017a, 2017b). Internal cooling is highly practical and can be implemented separately or in addition to externally applied strategies (e.g., ice baths, ice jackets) to benefit from the potentiating effects of the combination of cooling techniques (Hasegawa et al., 2006) immediately before exercise. Further discussion of external and combined cooling techniques can be found in existing comprehensive reviews (Ross et al., 2013; Stevens et al., 2017b). It is important to recognize that effective strategies are also required to fit within the rules and schedules of competition and be practical to implement.

As ice is a more powerful cooling agent due to the thermal energy required to phase change a solid into liquid (Jay \& Morris, 2018; Ross et al., 2013), ice-slurry beverages allow for a greater heat storage capacity and level of thermal comfort than a similar volume of ingested fluid (Ihsan et al., 2010; Siegel et al., 2010; Siegel et al., 2011). Adding glycerol and other solutes (e.g., carbohydrate and/or electrolytes) lowers the freezing point, allowing the formation of a supercooled crystalline liquid served at subzero temperatures. While improving consistency so that the frozen beverage can be readily ingested using a straw, a practical limitation may involve the discomfort associated with subsequent brain freeze (i.e., sphenopalatine ganglioneuralgia).

Preexercise ingestion of cold (Burdon et al., 2010b; Lee et al., 2008) and ice-slurry (Burdon et al., 2013; Dugas, 2011; Siegel et al., 2012) beverages may be effective in cooling athletes during exercise in hot, humid, and still environments. However, this may not be the case in warm, dry, and windy environments, where evaporative heat loss potential is greater; this is due to a reduction in sweating that occurs when consuming cold beverages following the stimulation of abdominal thermoreceptors (Jay \& Morris, 2018). Nevertheless, performance advantages may still be seen in response to a perceptual benefit. Although the value of creating a larger heat sink by internal cooling alone may be modest in comparison with the thermal challenges of the event (i.e., exogenous and endogenous heat stress), there is strong evidence for oral temperature-sensitive regions of the brain being activated when cold fluid is placed in the mouth (Guest et al., 2007), enhancing the perception of thermal comfort.

\section{Other Nutritional Strategies to Enhance Thermal Comfort}

Another nutrition strategy that alters thermal sensation is the use of L(-) menthol. Menthol is a cyclic terpene alcohol found in mint leaves, which activates oropharyngeal cold receptors and increases the threshold temperature for their activation, creating a feeling of coolness (McKemy et al., 2002; Peier et al., 2002). Menthol can be applied externally to skin or clothing as a gel or spray, but the most effective method is oral ingestion in the form of mouth rinse or an aromatized beverage (Stevens \& Best, 2016). The cooling effect of menthol has the potential to improve performance in hot and/or humid conditions, with observations of enhanced exercise capacity following mouth rinsing with a liquid menthol solution during exercise (Mündel \& Jones, 2010). The beneficial effect of menthol can be further enhanced by administering menthol at cold $\left(\sim 3^{\circ} \mathrm{C}\right)$ temperatures (Trong et al., 2015) or in the form of an ice slurry (Riera et al., 2014; Trong et al., 2015). Indeed, performance was enhanced by the combination of thermal and sensory cooling achieved by ingesting a menthol-slushie before and during a 20-km cycling time trial (Riera et al., 2014). It is recommended that athletes experiment to determine the concentration and amount of ingested menthol solution that is tolerable and beneficial. The suggested preparation involves the addition of $0.1-0.5 \mathrm{~g}$ of crushed menthol crystals (dissolved in alcohol) to $1 \mathrm{~L}$ of water or the use of a commercial premixed menthol/alcohol solution (Stevens \& Best, 2016). Light green or blue menthol solutions appear to illicit the most positive response, potentially due to their subjective qualities and association with coolness (Best et al., 2018). Extreme caution should be taken if preparing menthol solutions from basic ingredients for oral ingestion. Given the small quantity of menthol required and potential for toxicity if not prepared correctly (e.g., burning, irritation, pain, and potential fatality in large quantities; Kumar et al., 2016), it is suggested that practitioners, coaches, and athletes utilize commercially available products wherever possible.

\section{Practical Implementation of Nutrition Plans for the Heat}

The ability of athletes, coaches, and support staff to implement nutrition and hydration strategies to optimize health and performance in hot environments is frequently compromised by specific physiological, cultural, and practical challenges unique to particular sports or athlete subgroups. The following section describes these challenges in a variety of sports settings, with practical recommendations summarized in Table 3 .

\section{Team Sports}

Training and competition for team sports are undertaken in varying seasonal and geographical locations, requiring the development of population- and environment-specific plans to address these challenges. Indeed, team sports present unique challenges because the thermal strain between players (e.g., different positions) can differ significantly and vary based on match location. Nevertheless, team sports may offer some useful characteristics for heat management in the form of player rotations and routine breaks within the game. The intermittent nature of many team sports offers some respite from the heat-generation aspects of exercise, while also providing good opportunities to implement strategies for thermal strain management and nutrition goals. Some team sports have rules that impede access to fluid during lengthy competition periods (e.g., original Fédération Internationale de Football Association rules limit fluid intake to the break between 45 -min halves). When team sports are played in hot environmental conditions, local authorities or match officials should have the opportunity and understanding to implement specific rules or conditions that are better suited to the environment (e.g., Fédération Internationale de Football Association updated the Heat Policy with additional 


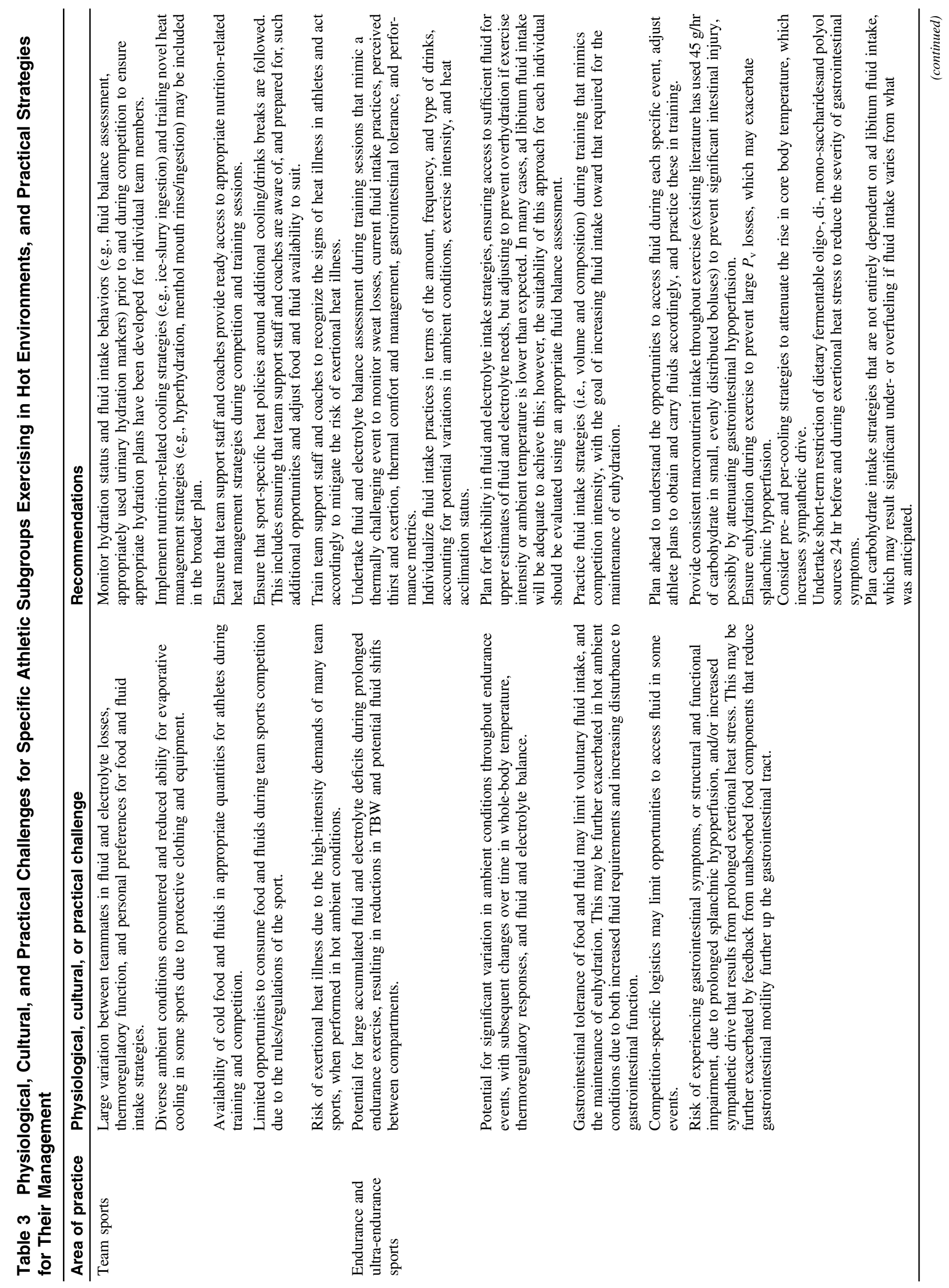




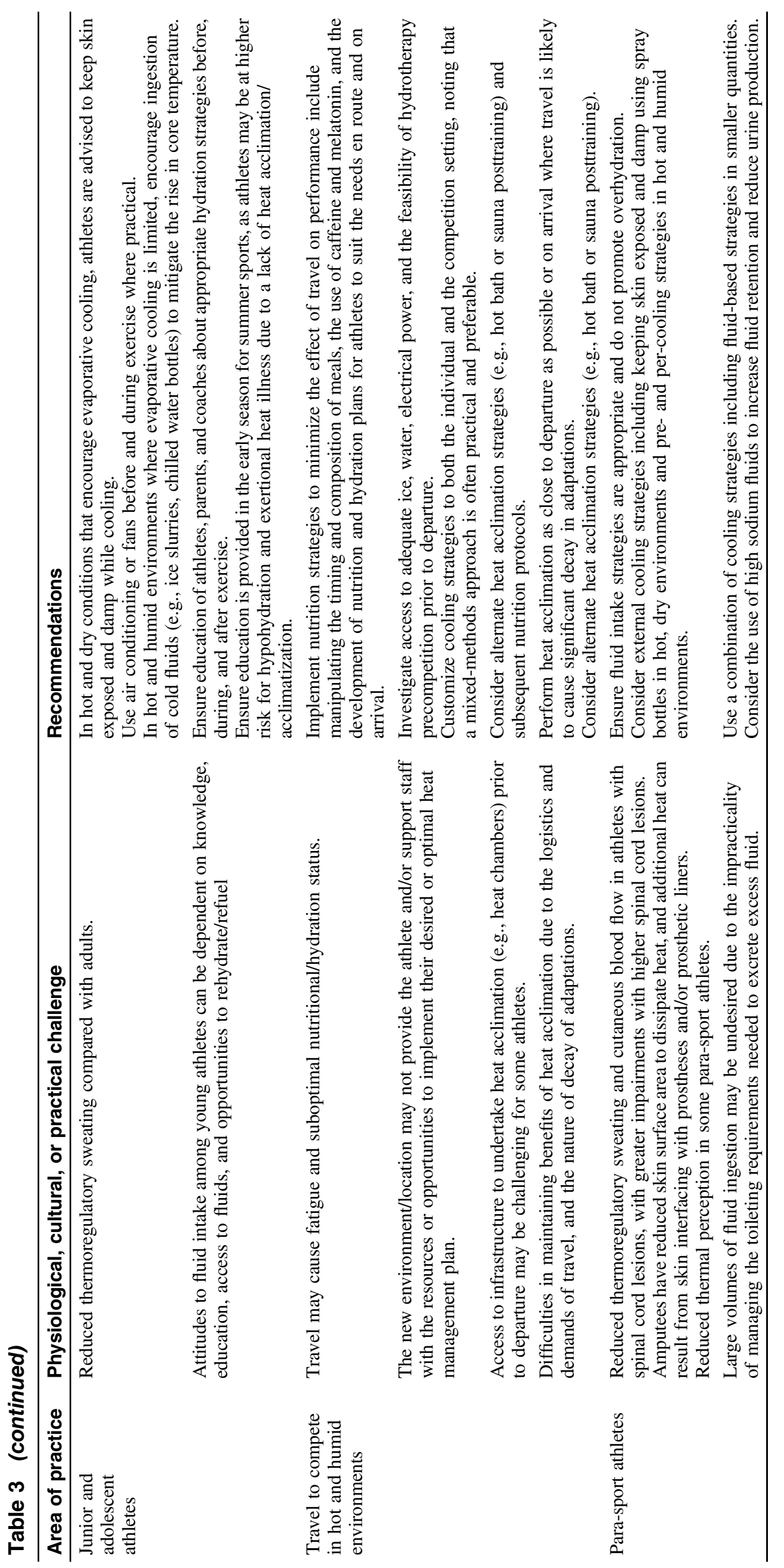


cooling/drinking breaks at 30 and 75 min when wet-bulb globe temperature exceeds $32{ }^{\circ} \mathrm{C}$ ). Teams should be aware of, and able to exploit, opportunities to implement better plans for hydration and heat management.

\section{Endurance and Ultra-Endurance Sports}

Endurance (30 min to $4 \mathrm{hr}$ ) and ultra-endurance ( $>4 \mathrm{hr}$ ) exercise encompasses a range of exercise modalities, terrain and environments. Sustained elevations in thermal strain during endurance exercise present unique physiological challenges to athletes, including large accumulated fluid and electrolyte deficits (Shirreffs \& Sawka, 2011), increased risk of gastrointestinal disturbance during exercise (Costa et al., 2019a), and EHI (Leon \& Bouchama, 2015). The unique challenges of endurance sports include the potential for large variations in ambient conditions within an event, as well as increased emphasis on during-event nutrition and hydration strategies due to the continuous nature of most sports. Practical considerations include the availability of nutrition supplies, the logistics of ingestion during exercise, and the interaction with gastrointestinal comfort/function. Endurance athletes can both under- and overconsume fluid during competitive events based on these factors, as well as erroneous calculations of likely sweat losses and misguided aspirations of performance enhancement (Burke et al., 2019). Indeed, the net effect of fluid intake strategies on performance is a complex trade-off between manipulations of physiology and homeostasis, perceptions of comfort and exertion, and the cost of the plan (e.g., time lost in obtaining and consuming fluids). Such issues are unlikely to be solved by conventional research techniques. The ability for endurance athletes to ingest food and fluids is frequently limited by gastrointestinal tolerance, as well as opportunities for consumption. For example, elite male marathon runners may allow less than $60 \mathrm{~s}$ to consume nutrition during competition (Beis et al., 2012), and anecdotal reports suggest great difficulty consuming and tolerating ideal fluid intake due to exercise intensity and the required ventilation.

\section{Junior and Adolescent Athletes}

Young athletes are typically considered to be at a thermoregulatory disadvantage compared with adults due to lowered sweat rates and higher surface area to body mass ratios. However, more recent reports suggest that when euhydrated and heat-acclimatized, young athletes face similar cardiovascular or thermoregulatory challenges during exercise as adults matched for fitness, hydration, and acclimation status (Bergeron, 2015; Bergeron et al., 2015; Rowland, 2008). Notwithstanding, during the transition from early childhood to late adolescence, it is important to accommodate greater sweat losses and potential increases in thermal strain and EHI risk that accompany physical growth, maturation, and enhanced fitness and athletic/sport skill. As such, combined strategies to manage heat stress in younger athletes may be more effective (e.g., fluid replacement to support evaporative losses and exposure to cool clothing/towels for conduction). Attitudes to fluid intake among young athletes can be dependent on knowledge, education, access to fluids, and opportunities to rehydrate/ refuel (Meyer et al., 2012). The extent to which biological sex influences the impact on hydration during exertional heat stress is still unclear, but men may be at greater risk of dehydration due to increases in muscle tissue (and subsequent water content) during adolescence (Meyer et al., 2012; Timmons et al., 2007).

\section{Travel to Compete in Hot and Humid Environments}

Travel for competition can add another layer of complexity to the challenge of exertional heat stress. The trip can contribute a range of factors that cause fatigue and suboptimal nutritional/hydration status (Fowler et al., 2016), while the new environment/location may not provide the athlete (or support staff) with the resources or opportunities to implement their desired or optimal heat management plan. Heat acclimation prior to travel for competition in hot and/or humid environments is a commonly employed strategy, particularly among elite and professional athletes. However, there are many complexities involved in implementing an optimal acclimation plan, especially when the athlete is traveling from a cold location to compete in a vastly different environment. Accessing sophisticated resources (e.g., heat chambers) prior to departure may be not feasible for some athletes, and alternate heat acclimation strategies (e.g., hot bath or sauna posttraining) and subsequent nutrition protocols may be required (Saunders et al., 2019). However, even when heat acclimation is achieved, there may be difficulties in maintaining its benefits due to the logistics and demands of travel. The rate of decay of physiological benefits of heat acclimation is reported to be $\sim 2.5 \%$ per day without heat exposure (Daanen et al., 2018) and is an important consideration in relation to the travel itinerary (Saunders et al., 2019). The maintenance of heat acclimation adaptations and the adjustment of the athlete's nutrition and hydration strategies to suit the environmental conditions upon arrival is imperative. Real-world competition settings can present logistical challenges for established pre- and per-cooling strategies. The practicalities of providing ice slurries, ice vests, plunge baths, and ice towels at the competition venue must be considered.

\section{Para-Sports}

Para-sport athletes are classified by their impairment type (i.e., visual, intellectual, or physical) and compete across a wide range of sports. Several conditions present higher risk of thermal strain than is experienced by able-bodied athletes (Pritchett et al., 2019). Spinal cord injury has received most attention in the sports science literature, as it is associated with complete or partial loss of neural function below the level of injury and a failure to initiate normal thermoregulatory mechanisms like sweating and skin blood flow redistribution. Athletes with spinal cord injuries experience greater increases in core temperature at a given exercise and/or heat load than able-bodied athletes, which is more pronounced with higher spinal cord lesions (Price \& Campbell, 1999). Fluid needs are lower due to reduced sweat rates, which along with practicalities around toileting underscores the need for an individualized hydration plan (Pritchett et al., 2019).

Other impairment types also face challenges. For example, $60-80 \%$ of people with multiple sclerosis have worsening physical and cognitive symptoms with heat stress (Davis et al., 2010). Athletes with cerebral palsy face increased fatigue and symptomology, likely due to increased metabolic heat production from movement inefficiency (Pritchett et al., 2019). Amputees have reduced skin surface area to dissipate heat, and additional heat can result from skin interfacing with prostheses and/or prosthetic liners (Andrews et al., 2016). Finally, visually impaired athletes may have reduced pace and hydration awareness, a potential challenge in hot conditions (Pritchett et al., 2019). These specific differences underscore the need for individual assessments of heat tolerance, fluid needs, and strategies to manage core temperature in para-sport athletes. 


\section{Conclusion}

Exercise in the heat is associated with varying levels of thermal stress and potential effects on the health and performance of the athlete. Nutritional strategies before, during, and after exercise can address different aspects of exertional heat stress. These strategies need to be implemented using protocols that are individualized and made practical for the specific needs of the athlete and their event.

\section{References}

Adams, J.D., Sekiguchi, Y., Suh, H.G., Seal, A.D., Sprong, C.A., Kirkland, T.W., \& Kavouras, S.A. (2018). Dehydration impairs cycling performance, independently of thirst: A blinded study. Medicine \& Science in Sports \& Exercise, 50(8), 1697-1703. PubMed ID: 29509643 doi:10.1249/MSS.0000000000001597

Allen, D.G., Lamb, G.D., \& Westerblad, H. (2008). Skeletal muscle fatigue: Cellular mechanisms. Physiological Reviews, 88(1), 287332. PubMed ID: 18195089 doi:10.1152/physrev.00015.2007

Andrews, A.M., Deehl, C., Rogers, R.L., \& Pruziner, A.L. (2016). Core temperature in service members with and without traumatic amputations during a prolonged endurance event. Military Medicine, 181(Suppl. 4), 61-65. doi:10.7205/MILMED-D-15-00515

Armstrong, L.E. (2007). Assessing hydration status: The elusive gold standard. Journal of the American College of Nutrition, 26(Suppl. 5), 575S-584S. doi:10.1080/07315724.2007.10719661

Armstrong, L.E., \& Maresh, C.M. (1991). The induction and decay of heat acclimatization in trained athletes. Sports Medicine, 12(5), 302-312. PubMed ID: 1763248 doi:10.2165/00007256-199112050-00003

Aughey, R.J., Goodman, C.A., \& McKenna, M.J. (2014). Greater chance of high core temperatures with modified pacing strategy during team sport in the heat. Journal of Science and Medicine in Sport, 17(1), 113-118. PubMed ID: 23689104 doi:10.1016/j.jsams.2013.02.013

Baker, L.B. (2017). Sweating rate and sweat sodium concentration in athletes: A review of methodology and intra/interindividual variability. Sports Medicine, 47(Suppl. 1), 111-128. PubMed ID: 28332116 doi:10.1007/s40279-017-0691-5

Baker, L.B., Barnes, K.A., Anderson, M.L., Passe, D.H., \& Stofan, J.R. (2016). Normative data for regional sweat sodium concentration and whole-body sweating rate in athletes. Journal of Sports Sciences, 34(4), 358-368. PubMed ID: 26070030 doi:10.1080/02640414. 2015.1055291

Baker, L.B., Ungaro, C.T., Barnes, K.A., Nuccio, R.P., Reimel, A.J., \& Stofan, J.R. (2014). Validity and reliability of a field technique for sweat $\mathrm{Na}^{+}$and $\mathrm{K}^{+}$analysis during exercise in a hot-humid environment. Physiological Reports, 2(5), e12007. PubMed ID: 24793982 doi:10.14814/phy2.12007

Baker, L.B., Ungaro, C.T., Sopeña, B.C., Nuccio, R.P., Reimel, A.J., Carter, J.M., . . Barnes, K.A. (2018). Body map of regional vs. whole body sweating rate and sweat electrolyte concentrations in men and women during moderate exercise-heat stress. Journal of Applied Physiology, 124(5), 1304-1318. PubMed ID: 29420145 doi:10. 1152/japplphysiol.00867.2017

Barnes, K.A., Anderson, M.L., Stofan, J.R., Dalrymple, K.J., Reimel, A.J., Roberts, T.J., . . Baker, L.B. (2019). Normative data for sweating rate, sweat sodium concentration, and sweat sodium loss in athletes: An update and analysis by sport. Journal of Sports Sciences, 37(20), 23562366. PubMed ID: 31230518 doi:10.1080/02640414.2019.1633159

Barrett, K.E. (2012). Epithelial biology in the gastrointestinal system: Insights into normal physiology and disease pathogenesis. Journal of Physiology, 590(3), 419-420. PubMed ID: 22298901 doi:10.1113/ jphysiol.2011.227058
Beis, L.Y., Wright-White, M., Fudge, B.W., Noakes, T.D., \& Pitsiladis, Y.P. (2012). Drinking behaviours of elite male runners during marathon competition. Clinical Journal of Sports Medicine, 22(3), 254-261. doi:10.1097/JSM.0b013e31824a55d7

Bergeron, M.F. (2003). Heat cramps: Fluid and electrolyte challenges during tennis in the heat. Journal of Science and Medicine in Sport, 6(1), 19-27. PubMed ID: 12801207 doi:10.1016/S1440-2440(03) 80005-1

Bergeron, M.F. (2015). Training and competing in the heat in youth sports: No sweat? British Journal of Sports Medicine, 49(13), 837-839. PubMed ID: 26084522 doi:10.1136/bjsports-2015-094662

Bergeron, M.F., Mountjoy, M., Armstrong, N., Chia, M., Cote, J., Emery, C.A., . . . Engebretsen, L. (2015). International Olympic Committee consensus statement on youth athletic development. British Journal of Sports Medicine, 49(13), 843-851. PubMed ID: 26084524 doi:10. 1136/bjsports-2015-094962

Bergh, U., \& Ekblom, B. (1979). Influence of muscle temperature on maximal strength and power output in human skeletal muscles. Acta Physiologica Scandinavica, 107(1), 33-37. PubMed ID: 525366 doi:10.1111/j.1748-1716.1979.tb06439.x

Best, R., Spears, I.R., Hurst, P., \& Berger, N.J.A. (2018). The development of a menthol solution for use during sport and exercise. Beverages, 4(2), 44. doi:10.3390/beverages4020044

Bovell, D. (2015). The human eccrine sweat gland: Structure, function and disorders. Journal of Local and Global Health Science, 2015(1), 5. doi:10.5339/jlghs.2015.5

Bruck, K., \& Olschewski, H. (1987). Body temperature related factors diminishing the drive to exercise. Canadian Journal of Physiology and Pharmacology, 65(6), 1274-1280. PubMed ID: 3621076

Burdon, C., O'Connor, H., Gifford, J., Shirreffs, S., Chapman, P., \& Johnson, N. (2010a). Effect of drink temperature on core temperature and endurance cycling performance in warm, humid conditions. Journal of Sports Sciences, 28(11), 1147-1156. doi:10.1080/ 02640414.2010.489197

Burdon, C.A., Hoon, M.W., Johnson, N.A., Chapman, P.G., \& O’Connor, H.T. (2013). The effect of ice slushy ingestion and mouthwash on thermoregulation and endurance performance in the heat. International Journal of Sport Nutrition and Exercise Metabolism, 23(5), 458-469. doi:10.1123/ijsnem.23.5.458

Burdon, C.A., Johnson, N.A., Chapman, P.G., \& O'Connor, H.T. (2012). Influence of beverage temperature on palatability and fluid ingestion during endurance exercise: A systematic review. International Journal of Sport Nutrition and Exercise Metabolism, 22(3), 199-211. PubMed ID: 22693241 doi:10.1123/ijsnem.22.3.199

Burdon, C.A., O’Connor, H.T., Gifford, J.A., \& Shirreffs, S.M. (2010b). Influence of beverage temperature on exercise performance in the heat: A systematic review. International Journal of Sport Nutrition and Exercise Metabolism, 20(2), 166-174. doi:10.1123/ijsnem.20. 2.166

Burke, L.M., Castell, L.M., Casa, D.J., Close, G.L., Costa, R.J.S., Desbrow, B., . . . Stellingwerff, T. (2019). International Association of Athletics Federations Consensus Statement 2019: Nutrition for athletics. International Journal of Sport Nutrition and Exercise Metabolism, 29(2), 73-84. PubMed ID: 30952204 doi:10.1123/ ijsnem.2019-0065

Campagnolo, N., Iudakhina, E., Irwin, C., Schubert, M., Cox, G.R., Leveritt, M., \& Desbrow, B. (2017). Fluid, energy and nutrient recovery via ad libitum intake of different fluids and food.Physiology \& Behavior, 171, 228-235. PubMed ID: 28104353 doi:10.1016/ j.physbeh.2017.01.009

Cheuvront, S.N., \& Kenefick, R.W. (2017). CORP: Improving the status quo for measuring whole body sweat losses. Journal of Applied 
Physiology, 123(3), 632-636. PubMed ID: 28684591 doi:10.1152/ japplphysiol.00433.2017

Cheuvront, S.N., Montain, S.J., \& Sawka, M.N. (2007). Fluid replacement and performance during the marathon. Sports Medicine, 37(4-5), 353-357. doi:10.2165/00007256-200737040-00020

Chinevere, T.D., Kenefick, R.W., Cheuvront, S.N., Lukaski, H.C., \& Sawka, M.N. (2008). Effect of heat acclimation on sweat minerals. Medicine \& Science in Sports \& Exercise, 40(5), 886-891. PubMed ID: 18408609 doi:10.1249/MSS.0b013e3181641c04

Costa, R.J.S., Camões-Costa, V., Snipe, R.M.J., Dixon, D., Russo, I., \& Huschtscha, Z. (2019b). The impact of exercise-induced hypohydration on gastrointestinal integrity, function, symptoms, and systemic endotoxin and inflammatory profile. Journal of Applied Physiology, 126(5), 1281-1291. doi:10.1152/japplphysiol.01032.2018

Costa, R.J.S., Gaskell, S.K., McCubbin, A.J., \& Snipe, R.M.J. (2019a). Exertional-heat stress-associated gastrointestinal perturbations during Olympic sports: Management strategies for athletes preparing and competing in the 2020 Tokyo Olympic Games. Temperature. Advance online publication. doi:10.1080/23328940.2019.1597676

Costa, R.J.S., Snipe, R.M.J., Kitic, C., \& Gibson, P. (2017). Systematic review: Exercise-induced gastrointestinal syndrome- implications for health and disease. Alimentary Pharmacology and Therapeutics, 46(3), 246-265. doi:10.1111/apt.14157

Cramer, M.N., \& Jay, O. (2019). Cores of reproducibility in physiology: Partitional calorimetry. Journal of Applied Physiology, 126(2), 267277. PubMed ID: 30496710 doi:10.1152/japplphysiol.00191.2018

Daanen, H.A.M., Racinais, S., \& Périard, J.D. (2018). Heat acclimation decay and re-induction: A systematic review and meta-analysis. Sports Medicine, 48(2), 409-430. PubMed ID: 29129022 doi:10. 1007/s40279-017-0808-x

Davis, S.L., Wilson, T.E., White, A.T., \& Frohman, E.M. (2010). Thermoregulation in multiple sclerosis. Journal of Applied Physiology, 109(5), 1531-1537. PubMed ID: 20671034 doi:10. 1152/japplphysiol.00460.2010

Dugas, J. (2011). Ice slurry ingestion increases running time in the heat. Clinical Journal of Sport Medicine, 21(6), 541-542. PubMed ID: 22064722 doi:10.1097/01.jsm.0000407930.13102.42

Earp, J.E., Stearns, R.L., Stranieri, A., Agostinucci, J., Lepley, A.S., Matson, T., \& Ward-Ritacco, C.L. (2019). Electrolyte beverage consumption alters electrically induced cramping threshold. Muscle Nerve, 60(5), 598-603. PubMed ID: 31350753 doi:10.1002/mus. 26650

Ely, M.R., Cheuvront, S.N., Roberts, W.O., \& Montain, S.J. (2007). Impact of weather on marathon-running performance. Medicine \& Science in Sports \& Exercise, 39(3), 487-493. doi:10.1249/mss. 0b013e31802d3aba

Evans, G.H., James, L.J., Shirreffs, S.M., \& Maughan, R.J. (2017). Optimizing the restoration and maintenance of fluid balance after exercise-induced dehydration. Journal of Applied Physiology, 122(4), 945-951. PubMed ID: 28126906 doi:10.1152/japplphysiol. 00745.2016

Febbraio, M.A., Snow, R.J., Stathis, C.G., Hargreaves, M., \& Carey, M.F. (1994). Effect of heat stress on muscle energy metabolism during exercise. Journal of Applied Physiology, 77(6), 2827-2831. PubMed ID: 7896628 doi:10.1152/jappl.1994.77.6.2827

Fitts, R.H. (1994). Cellular mechanisms of muscle fatigue. Physiological Reviews, 74(1), 49-94. PubMed ID: 8295935 doi:10.1152/physrev. 1994.74.1.49

Fowler, P.M., Duffield, R., Lu, D., Hickmans, J.A., \& Scott, T.J. (2016). Effects of long-haul transmeridian travel on subjective jet-lag and self-reported sleep and upper respiratory symptoms in professional rugby league players. International Journal of Sports Physiology and
Performance, 11(7), 876-884. PubMed ID: 26788986 doi:10.1123/ ijspp.2015-0542

Gagge, A.P., \& Gonzalez, R.R. (1996). Mechanisms of heat exchange: Biophysics and physiology. In M.J. Fregly\& C.M. Blatteis (Eds.), Handbook of physiology, environmental physiology (pp. 45-84). Bethesda, MD: American Physiological Society.

Gagnon, D., \& Crandall, C.G. (2018). Sweating as a heat loss thermoeffector. Handbook of Clinical Neurology, 156, 211-232.

Gerret, N., Kingma, B.R.M., Sluijter, R., \& Daanan, H.A.M. (2019). Ambient conditions prior to Tokyo 2020 Olympic and Paralympic games: Considerations for acclimation or acclimatization strategies. Frontiers in Physiology, 10, 414.

Girard, O., Brocherie, F., \& Bishop, D.J. (2015). Sprint performance under heat stress: A review. Scandinavian Journal of Medicine \& Science in Sports, 25(Suppl. 1), 79-89. doi:10.1111/sms.12437

Gisolfi, C.V., \& Cohen, J.S. (1979). Relationships among training, heat acclimation, and heat tolerance in men and women: The controversy revisited. Medicine and Science in Sports, 11(1), 56-59. PubMed ID: 481157

Goulet, E.D., Aubertin-Leheudre, M., Plante, G.E., \& Dionne, I.J. (2007). A meta-analysis of the effects of glycerol-induced hyperhydration on fluid retention and endurance performance. International Journal of Sport Nutrition and Exercise Metabolism, 17(4), 391-410. PubMed ID: 17962713 doi:10.1123/ijsnem.17.4.391

Goulet, E.D.B., De La Flore, A., Savoie, F.A., \& Gosselin, J. (2018). Salt + glycerol-induced hyperhydration enhances fluid retention more than salt- or glycerol-induced hyperhydration. International Journal of Sport Nutrition and Exercise Metabolism, 28(3), 246-252. PubMed ID: 29140136 doi:10.1123/ijsnem.2017-0310

Goulet, E.D.B., \& Hoffman, M.D. (2019). Impact of ad libitum versus programmed drinking on endurance performance: A systematic review with meta-analysis. Sports Medicine, 49(2), 221-232. PubMed ID: 30659500 doi:10.1007/s40279-018-01051-z

Grootjans, J., Lenaerts, K., Buurman, W.A., Dejong, C.H.C., \& Derikx, J.P.M. (2016). Life and death at the mucosal-luminal interface: New perspectives on human intestinal ischemia-reperfusion. World Journal of Gastroenterology, 22(9), 2760-2770. PubMed ID: 26973414 doi:10.3748/wjg.v22.i9.2760

Guest, S., Grabenhorst, F., Essick, G., Chen, Y., Young, M., McGlone, F., . . . Rolls, E.T. (2007). Human cortical representation of oral temperature. Physiology \& Behavior, 92(5), 975-984. doi:10.1016/ j.physbeh.2007.07.004

Hamouti, N., Fernandez-Elias, V.E., Ortega, J.F., \& Mora-Rodriguez, R. (2014). Ingestion of sodium plus water improves cardiovascular function and performance during dehydrating cycling in the heat. Scandinavian Journal of Medicine \& Science in Sports, 24(3), 507-518. PubMed ID: 23253191 doi:10.1111/sms.12028

Hasegawa, H., Takatori, T., Komura, T., \& Yamasaki, M. (2006). Combined effects of pre-cooling and water ingestion on thermoregulation and physical capacity during exercise in a hot environment. Journal of Sports Sciences, 24(1), 3-9. PubMed ID: 16368609 doi:10.1080/ 02640410400022185

Hew-Butler, T., Rosner, M.H., Fowkes-Godek, S., Dugas, J.P., Hoffman, M.D., Lewis, D.P., . . . Verbalis, J.G. (2015). Statement of the 3rd International exercise-associated hyponatremia consensus development conference, Carlsbad, California, 2015. British Journal of Sports Medicine, 49(22), 1432-1446. PubMed ID: 26227507 doi:10. 1136/bjsports-2015-095004

Hoffman, M.D., Stellingwerff, T., \& Costa, R.J.S. (2019). Considerations for ultra-endurance activities: Part 2-Hydration. Research in Sports Medicine, 27(2), 182-194. PubMed ID: 30056755 doi:10.1080/ 15438627.2018.1502189 
Holland, J.J., Skinner, T.L., Irwin, C.G., Leveritt, M.D., \& Goulet, E.D.B. (2017). The influence of drinking fluid on endurance cycling performance: A meta-analysis. Sports Medicine, 47(11), 2269-2284. PubMed ID: 28497286 doi:10.1007/s40279-017-0739-6

Holmes, N.A., Bates, G., Zhao, Y., Sherriff, J., \& Miller, V. (2016). The effect of exercise intensity on sweat rate and sweat sodium and potassium losses in trained endurance athletes. Annals of Sports Medicine and Research, 3(2), 1063-1067.

Holzer, P., Farzi, A., Hassan, A.M., Zenz, G., Ja冈an, A., \& Reichmann, F. (2017). Visceral Inflammation and Immune Activation Stress the Brain. Frontiers in Immunology, 8, 1613. PubMed ID: 29213271 doi:10.3389/fimmu.2017.01613

Horner, K.M., Schubert, M.M., Desbrow, B., Byrne, N.M., \& King, N.A. (2015). Acute exercise and gastric emptying: A meta-analysis and implications for appetite control. Sports Medicine, 45(5), 659-678. PubMed ID: 25398225 doi:10.1007/s40279-014-0285-4

Ihsan, M., Landers, G., Brearley, M., \& Peeling, P. (2010). Beneficial effects of ice ingestion as a precooling strategy on 40-km cycling time-trial performance. International Journal of Sports Physiology and Performance, 5(2), 140-151. doi:10.1123/ijspp.5.2.140

James, L.J., Moss, J., Henry, J., Papadopoulou, C., \& Mears, S.A. (2017). Hypohydration impairs endurance performance: A blinded study. Physiological Reports, 5(12), e13315. PubMed ID: 28637708 doi:10. 14814/phy2.13315

Jay, O., \& Morris, N.B. (2018). Does cold water or ice slurry ingestion during exercise elicit a net body cooling effect in the heat? Sports Medicine, 48(Suppl. 1), 17-29. PubMed ID: 29368184 doi:10.1007/ s40279-017-0842-8

Jeukendrup, A.E., \& Moseley, L. (2010). Multiple transportable carbohydrates enhance gastric emptying and fluid delivery. Scandinavian Journal of Medicine \& Science in Sports, 20(1), 112-121. PubMed ID: 19000102 doi:10.1111/j.1600-0838.2008.00862.x

Kenefick, R.W., Cheuvront, S.N., Palombo, L.J., Ely, B.R., \& Sawka, M.N. (2010). Skin temperature modifies the impact of hypohydration on aerobic performance. Journal of Applied Physiology, 109(1), 79-86. PubMed ID: 20378704 doi:10.1152/japplphysiol. 00135.2010

Kumar, A., Baitha, U., Aggarwal, P., \& Jamshed, N. (2016). A fatal case of menthol poisoning. International Journal of Applied and Basic Medical Research, 6(2), 137-139. PubMed ID: 27127746 doi:10. 4103/2229-516X.179015

Lau, W.Y., Kato, H., \& Nosaka, K. (2019). Water intake after dehydration makes muscles more susceptible to cramp but electrolytes reverse that effect. BMJ Open Sport \& Exercise Medicine, 5(1), e000478. PubMed ID: 30899546 doi:10.1136/bmjsem-2018-000478

Layer, P., Peschel, S., Schlesinger, T., \& Goebell, H. (1990). Human pancreatic secretion and intestinal motility: Effects of ileal nutrient perfusion. American Journal of Physiology, 258(2, Pt. 1), G196-G201.

Lee, J.K., Shirreffs, S.M., \& Maughan, R.J. (2008). Cold drink ingestion improves exercise endurance capacity in the heat. Medicine \& Science in Sports \& Exercise, 40(9), 1637-1644. doi:10.1249/MSS. 0b013e318178465d

Leon, L.R., \& Bouchama, A. (2015). Heat stroke. Comprehensive Physiology, 5(2), 611-647. PubMed ID: 25880507

Lichton, I.J. (1957). Competition between sweat glands and kidneys for salt and water in man. Journal of Applied Physiology, 11(2), 223-226. PubMed ID: 13475170 doi:10.1152/jappl.1957.11.2.223

Malczewska-Lenczowska, J., Sitkowski, D., Orysiak, J., Pokrywka, A., \& Szygula, Z. (2013). Total haemoglobin mass, blood volume and morphological indices among athletes from different sport disciplines. Archives of Medical Science, 9(5), 780-787. PubMed ID: 24273557 doi:10.5114/aoms.2013.36926
Maughan, R.J., Shirreffs, S.M., \& Leiper, J.B. (2007). Errors in the estimation of hydration status from changes in body mass. Journal of Sports Sciences, 25(7), 797-804. PubMed ID: 17454547 doi:10. 1080/02640410600875143

Maughan, R.J., Watson, P., Cordery, P.A., Walsh, N.P., Oliver, S.J., Dolci, A., . . . Galloway, S.D. (2016). A randomized trial to assess the potential of different beverages to affect hydration status: Development of a beverage hydration index. American Journal of Clinical Nutrition, 103(3), 717-723. PubMed ID: 26702122 doi:10.3945/ ajen.115.114769

McCartney, D., Irwin, C., Cox, G.R., \& Desbrow, B. (2018). Fluid, energy, and nutrient recovery via ad libitum intake of different commercial beverages and food in female athletes. Applied Physiology, Nutrition, and Metabolism, 44(1), 37-46. PubMed ID: 29953820 doi:10.1139/ apnm-2018-0176

McCartney, D., Irwin, C., Cox, G.R., \& Desbrow, B. (2019). The effect of different post-exercise beverages with food on ad libitum fluid recovery, nutrient provision, and subsequent athletic performance. Physiology \& Behavior, 201, 22-30. PubMed ID: 30552922 doi:10. 1016/j.physbeh.2018.12.013

McCubbin, A.J., \& Costa, R.J.S. (2018). Impact of sodium ingestion during exercise on endurance performance: A systematic review. International Journal of Sports Science, 8(3), 97-107.

McCubbin, A.J., Cox, G.R., \& Costa, R.J.S. (2019b). Sodium intake beliefs, information sources and intended practices of endurance athletes before and during exercise. International Journal of Sport Nutrition and Exercise Metabolism, 29(4), 371-381.

McCubbin, A.J., Lopez, M.B., Cox, G.R., Caldwell Odgers, J.N., \& Costa, R.J.S. (2019a). Impact of 3-day high and low dietary sodium intake on sodium status in response to exertional-heat stress: A double-blind randomized control trial. European Journal of Applied Physiology, 119, 2105-2118. doi:10.1007/s00421-019-04199-2

McKemy, D.D., Neuhausser, W.M., \& Julius, D. (2002). Identification of a cold receptor reveals a general role for TRP channels in thermosensation. Nature, 416(6876), 52-58. PubMed ID: 11882888 doi:10. 1038/nature719

Meyer, F., Volterman, K., Timmons, B., \& Boguslaw, W. (2012). Fluid balance and dehydration in the young athlete: Assessment considerations and effects on health and performance. American Journal of Lifestyle Medicine, 5(5), 1-13.

Miall, A., Khoo, A., Rauch, C., Snipe, R.M.J., Camões-Costa, V., Gibson, P.R., \& Costa, R.J.S. (2018). Two weeks of repetitive gut-challenge reduce exercise-associated gastrointestinal symptoms and malabsorption. Scandinavian Journal of Medicine \& Science in Sports, 28(2), 630-640. PubMed ID: 28508559 doi:10.1111/sms.12912

Mohr, M., Nybo, L., Grantham, J., \& Racinais, S. (2012). Physiological responses and physical performance during football in the heat. PLoS One, 7(6), e39202. PubMed ID: 22723963 doi:10.1371/journal.pone. 0039202

Montner, P., Stark, D.M., Riedesel, M.L., Murata, G., Robergs, R., Timms, M., \& Chick, T.W. (1996). Pre-exercise glycerol hydration improves cycling endurance time. International Journal of Sports Medicine, 17(1), 27-33. PubMed ID: 8775573 doi:10.1055/s-2007-972804

Morgan, R., Patterson, M., \& Nimmo, M. (2004). Acute effects of dehydration on sweat composition in men during prolonged exercise in the heat. Acta Physiologica Scandinavica, 182(1), 37-43. PubMed ID: 15329055 doi:10.1111/j.1365-201X.2004.01305.x

Morrison, S.F. (2011). 2010 Carl Ludwig distinguished lectureship of the APS neural control and autonomic regulation section: Central neural pathways for thermoregulatory cold defense. Journal of Applied Physiology, 110, 1137-1149. PubMed ID: 21270352 doi:10.1152/ japplphysiol.01227.2010 
Mündel, T., \& Jones, D.A. (2010). The effects of swilling an L(-)-menthol solution during exercise in the heat. European Journal of Applied Physiology, 109(1), 59-65. doi:10.1007/s00421-009-1180-9

Patterson, M.J., Stocks, J.M., \& Taylor, N.A. (2004). Sustained and generalized extracellular fluid expansion following heat acclimation. Journal of Physiology, 559(Pt. 1), 327-334. PubMed ID: 15218070 doi:10.1113/jphysiol.2004.063289

Peier, A.M., Moqrich, A., Hergarden, A.C., Reeve, A.J., Andersson, D.A., Story, G.M., . . . Patapoutian, A. (2002). A TRP channel that senses cold stimuli and menthol. Cell, 108(5), 705-715. PubMed ID: 11893340 doi:10.1016/S0092-8674(02)00652-9

Périard, J.D., Cramer, M.N., Chapman, P.G., Caillaud, C., \& Thompson, M.W. (2011). Cardiovascular strain impairs prolonged self-paced exercise in the heat. Experimental Physiology, 96(2), 134-144. PubMed ID: 20851861 doi:10.1113/expphysiol.2010.054213

Périard, J.D., \& Racinais, S. (2015). Self-paced exercise in hot and cool conditions is associated with the maintenance of \% VO2peak within a narrow range. Journal of Applied Physiology, 118(10), 1258-1265. PubMed ID: 25814635 doi:10.1152/japplphysiol.00084.2015

Périard, J.D., Racinais, S., \& Sawka, M.N. (2015). Adaptations and mechanisms of human heat acclimation: Applications for competitive athletes and sports. Scandinavian Journal of Medicine \& Science in Sports, 25(Suppl. 1), 20-38. doi:10.1111/sms.12408

Pires, W., Veneroso, C.E., Wanner, S.P., Pacheco, D.A.S., Vaz, G.C., Amorim, F.T., . . . Coimbra, C.C. (2017). Association between exercise-induced hyperthermia and intestinal permeability: A systematic review. Sports Medicine, 47(7), 1389-1403. PubMed ID: 27943148 doi:10.1007/s40279-016-0654-2

Pires, W., Wanner, S.P., Soares, D.D., \& Coimbra, C.C. (2018). Author's reply to Kitic: Comment on: "Association between exercise induced hyperthermia and intestinal permeability: A systematic review. Sports Medicine, 48(12), 2887-2889. PubMed ID: 30014333 doi:10.1007/ s40279-018-0954-9

Price, M.J., \& Campbell, I.G. (1999). Thermoregulatory responses of spinal cord injured and able-bodied athletes to prolonged upper body exercise and recovery. Spinal Cord, 37(11), 772-779. PubMed ID: 10578248 doi:10.1038/sj.sc.3100907

Pritchett, K., Pritchett, L., \& Broad, E. (2019). Chapter 5: Cooling and hydration for the para athlete. In E. Broad (Ed.), Sports nutrition for paralympic athletes (2nd ed., pp. 87-101). Boca Raton, FL: Taylor and Francis.

Racinais, S., Alonso, J.M., Coutts, A.J., Flouris, A.D., Girard, O., González-Alonso, J., . . . Périard, J.D. (2015). Consensus recommendations on training and competing in the heat. Scandinavian Journal of Medicine \& Science in Sports, 25(Suppl. 1), 6-19. doi:10. $1111 /$ sms. 12467

Riera, F., Trong, T.T., Sinnapah, S., \& Hue, O. (2014). Physical and perceptual cooling with beverages to increase cycle performance in a tropical climate. PLoS One, 9(8), e103718. PubMed ID: 25084009 doi:10.1371/journal.pone.0103718

Ross, M.L., Abbiss, C.R., Laursen, P., Martin, D.T., \& Burke, L.M. (2013). Precooling methods and their effects on athletic performance: A systematic review and practical applications. Sports Medicine, 43(3), 207-225. PubMed ID: 23329610 doi:10.1007/s40279-0120014-9

Rowland, T. (2008). Thermoregulation during exercise in the heat in children: Old concepts revisited. Journal of Applied Physiology, 105(2), 718-724. PubMed ID: 18079269 doi:10.1152/japplphysiol. 01196.2007

Russo, I., Camões-Costa, V., Gaskell, S.K., Porter, J., Burke, L.M., \& Costa, R.J.S. (2019). Systematic literature review: The effect of dairy milk on markers of recovery optimisation in response to endurance exercise. International Journal of Sports Science, 9(4), 69-85.

Sanders, B., Noakes, T.D., \& Dennis, S.C. (2001). Sodium replacement and fluid shifts during prolonged exercise in humans. European Journal of Applied Physiology, 84(5), 419-425. PubMed ID: 11417429 doi:10.1007/s004210000371

Sargeant, A.J. (1987). Effect of muscle temperature on leg extension force and short-term power output in humans. European Journal of Applied Physiology, 56(6), 693-698. doi:10.1007/BF00424812

Saunders, A.G., Dugas, J.P., Tucker, R., Lambert, M.I., \& Noakes, T.D. (2005). The effects of different air velocities on heat storage and body temperature in humans cycling in a hot, humid environment. Acta Physiologica Scandinavica, 183(3), 241-255. PubMed ID: 15743384 doi:10.1111/j.1365-201X.2004.01400.x

Saunders, P.U., Garvican-Lewis, L.A., Chapman, R.F., \& Périard, J.D. (2019). Special environments: Altitude and heat. International Journal of Sport Nutrition and Exercise Metabolism, 29(2), 210-219. PubMed ID: 30676138 doi:10.1123/ijsnem.2018-0256

Sawka, M.N., Burke, L.M., Eichner, E.R., Maughan, R.J., Montain, S.J., \& Stachenfeld, N.S. (2007). American College of Sports Medicine position stand. Exercise and fluid replacement. Medicine \& Science in Sports \& Exercise, 39(2), 377-390. PubMed ID: 17277604

Schmit, C., Duffield, R., Hausswirth, C., Brisswalter, J., \& Le Meur, Y. (2018). Optimizing heat acclimation for endurance athletes: Highversus low-intensity training. International Journal of Sports Physiology and Performance, 13(6), 816-823. PubMed ID: 28872380 doi:10.1123/ijspp.2017-0007

Schwellnus, M.P. (2009). Cause of Exercise Associated Muscle Cramps (EAMC)—Altered neuromuscular control, dehydration or electrolyte depletion? British Journal of Sports Medicine, 43(6), 401-408. PubMed ID: 18981039 doi:10.1136/bjsm.2008.050401

Shin, H.S., Ingram, J.R., McGill, A.T., \& Poppitt, S.D. (2013). Lipids, CHOs, proteins: Can all macronutrients put a 'brake' on eating? Physiology \& Behavior, 120, 114-123. PubMed ID: 23911804 doi:10.1016/j.physbeh.2013.07.008

Shirreffs, S.M., \& Sawka, M.N. (2011). Fluid and electrolyte needs for training, competition, and recovery. Journal of Sports Sciences, 29(Suppl. 1), S39-S46. doi:10.1080/02640414.2011.614269

Siegel, R., Maté, J., Brearley, M.B., Watson, G., Nosaka, K., \& Laursen, P.B. (2010). Ice slurry ingestion increases core temperature capacity and running time in the heat. Medicine \& Science in Sports \& Exercise, 42(4), 717-725. doi:10.1249/MSS.0b013e3181bf257a

Siegel, R., Maté, J., Watson, G., Nosaka, K., \& Laursen, P.B. (2011). The influence of ice slurry ingestion on maximal voluntary contraction following exercise-induced hyperthermia. European Journal of Applied Physiology, 111(10), 2517-2524. PubMed ID: 21360201 doi:10.1007/s00421-011-1876-5

Siegel, R., Maté, J., Watson, G., Nosaka, K., \& Laursen, P.B. (2012). Pre-cooling with ice slurry ingestion leads to similar run times to exhaustion in the heat as cold water immersion. Journal of Sports Sciences, 30(2), 155-165. PubMed ID: 22132792 doi:10.1080/ 02640414.2011 .625968

Sims, S.T., Rehrer, N.J., Bell, M.L., \& Cotter, J.D. (2007a). Preexercise sodium loading aids fluid balance and endurance for women exercising in the heat. Journal of Applied Physiology, 103(2), 534-541. doi:10.1152/japplphysiol.01203.2006

Sims, S.T., van Vliet, L., Cotter, J.D., \& Rehrer, N.J. (2007b). Sodium loading aids fluid balance and reduces physiological strain of trained men exercising in the heat. Medicine \& Science in Sports \& Exercise, 39(1), 123-130. doi:10.1249/01.mss.0000241639.97972.4a

Snipe, R.M.J., \& Costa, R.J.S. (2018). Does the temperature of water ingested during exertional-heat stress influence gastrointestinal 
injury, symptoms, and systemic inflammatory profile? Journal of Science and Medicine in Sport, 21(8), 771-776. PubMed ID: 29371075 doi:10.1016/j.jsams.2017.12.014

Stellingwerff, T., \& Cox, G.R. (2014). Systematic review: Carbohydrate supplementation on exercise performance or capacity of varying durations. Applied Physiology, Nutrition, and Metabolism, 39(9), 998-1011. PubMed ID: 24951297 doi:10.1139/apnm-2014-0027

Stevens, C.J., Bennett, K.J., Sculley, D.V., Callister, R., Taylor, L., \& Dascombe, B.J. (2017a). A comparison of mixed-method cooling interventions on preloaded running performance in the heat. Journal of Strength and Conditioning Research, 31(3), 620-629. doi:10. 1519/JSC.0000000000001532

Stevens, C.J., \& Best, R. (2016). Menthol: A fresh ergogenic aid for athletic performance. Sports Medicine, 47(6), 1035-1042. doi:10. 1007/s40279-016-0652-4

Stevens, C.J., Taylor, L., \& Dascombe, B.J. (2017b). Cooling during exercise: An overlooked strategy for enhancing endurance performance in the heat. Sports Medicine, 47(5), 829-841. doi:10.1007/ s40279-016-0625-7

Strid, H., Simrén, M., Störsrud, S., Stotzer, P., \& Sadik, R. (2011). Effect of heavy exercise on gastrointestinal transit in endurance athletes. Scandinavian Journal of Gastroenterology, 46, 673-677. PubMed ID: 21366388 doi:10.3109/00365521.2011.558110

Taylor, N.A.S., \& Cotter, J.D. (2006). Heat adaptation: Guidelines for the optimization of human performance. International Journal of Sports Medicine, 7(1), 33-57.

Timmons, B., Bar-Or, O., \& Riddell, M. (2007). Influence of age and pubertal status on substrate utilization during exercise with and without carbohydrate intake in healthy boys. Applied Physiology, Nutrition and Metabolism, 32, 416-425. doi:10.1139/H07-004

Trangmar, S.J., \& González-Alonso, J. (2017). New insights into the impact of dehydration on blood flow and metabolism during exercise.
Exercise and Sports Science Reviews, 45(3), 146-153. doi:10.1249/ JES.0000000000000109

Trong, T.T., Riera, F., Rinaldi, K., Briki, W., \& Hue, O. (2015). Ingestion of a cold temperature/menthol beverage increases outdoor exercise performance in a hot, humid environment. PLoS One, 10(4), e0123815. doi:10.1371/journal.pone.0123815

van Avesaat, M., Troost, F.J., Ripken, D., Hendriks, H.F., \& Masclee, A.A. (2015). Ileal brake activation: Macronutrient-specific effects on eating behavior? International Journal of Obesity, 39(2), 235-243. PubMed ID: 24957485 doi:10.1038/ijo.2014.112

van Citters, G.W., \& Lin, H.C. (2006). Ileal brake: Neuropeptidergic control of intestinal transit. Current Gastroenterology Reports, 8(5), 367-373. PubMed ID: 16968603 doi:10.1007/s11894-0060021-9

van Rosendal, S.P., Osborne, M.A., Fassett, R.G., \& Coombes, J.S. (2010). Guidelines for glycerol use in hyperhydration and rehydration associated with exercise. Sports Medicine, 40(2), 113-129. PubMed ID: 20092365 doi:10.2165/11530760-000000000-00000

van Wijck, K., Lenaerts, K., van Loon, L.J., Peters, W.H., Buurman, W.A., \& Dejong, C.H. (2011). Exercise-induced splanchnic hypoperfusion results in gut dysfunction in healthy men. PLoS One, 6(7), e22366. PubMed ID: 21811592 doi:10.1371/journal. pone. 0022366

Wendt, D., van Loon, L.J., \& Lichtenbelt, W.D. (2007). Thermoregulation during exercise in the heat: Strategies for maintaining health and performance. Sports Medicine, 37(8), 669-682. PubMed ID: 17645370 doi:10.2165/00007256-200737080-00002

Wingo, J.E., Casa, D.J., Berger, E.M., Dallis, W.O., Knight, J.C., \& McClung, J.M. (2004). Influence of a pre-exercise glycerol hydration beverage on performance and physiologic function during mountainbike races in the heat. Journal of Athletic Training, 39(2), 169-175. PubMed ID: 15173869 